\title{
Change in prostate volume during extreme hypo-fractionation analysed with MRI
}

\author{
Adalsteinn Gunnlaugsson ${ }^{1 *}$, Elisabeth Kjellén ${ }^{1}$, Oskar Hagberg², Camilla Thellenberg-Karlsson ${ }^{3}$,
} Anders Widmark ${ }^{3}$ and Per Nilsson ${ }^{4}$

\begin{abstract}
Background: Hypo-fractionated external beam radiotherapy with narrow CTV-PTV margins is increasingly applied for prostate cancer. This demands a precise target definition and knowledge on target location and extension during treatment. It is unclear how increase in fraction size affects changes in prostate volume during treatment. Our aim was to study prostate volume changes during extreme hypo-fractionation (7×6.1 Gy) by using sequential MRIs.
\end{abstract}

Methods: Twenty patients treated with extreme hypo-fractionation were recruited from an on-going prospective randomized phase III trial. An MRI scan was done before start of treatment, at mid treatment and at the end of radiotherapy. The prostate was delineated at each MRI and the volume and maximum extension in left-right, anterior-posterior and cranial-caudal directions were measured.

Results: There was a significant increase in mean prostate volume (14\%) at mid treatment as compared to baseline. The prostate volume remained enlarged (9\%) at the end of radiotherapy. Prostate swelling was most pronounced in the anterior-posterior and cranial-caudal directions.

Conclusions: Extreme hypo-fractionation induced a significant prostate swelling during treatment that was still present at the time of last treatment fraction. Our results indicate that prostate swelling is an important factor to take into account when applying treatment margins during short extreme hypo-fractionation, and that tight margins should be applied with caution.

Keywords: Hypo-fractionation, MRI, Prostate cancer, Radiotherapy, Swelling, Volume change

\section{Background}

The field of radiotherapy (RT) is rapidly evolving with new advanced treatment techniques and improved imaging. Implementation of magnetic resonance imaging (MRI) for segmentation together with sophisticated image guided radiotherapy (IGRT) techniques based on implanted fiducials has resulted in improved accuracy and precision in RT for prostate cancer [1-3]. A workflow based solely on MR, i.e. from prostate delineation to treatment planning and delivery, has been proposed and shown to reduce systematic uncertainties considerably compared to a conventional CT/MR-based workflow [4]. Evidence from prostate cancer radiotherapy trials shows that dose-escalation

\footnotetext{
* Correspondence: adalsteinn.gunnlaugsson@skane.se

'Department of Oncology, Skåne University Hospital, Lund University, 22185 Lund, Sweden

Full list of author information is available at the end of the article
}

improves outcome [5-8] with limited increase in toxicity $[9,10]$. The latter is partly due to a reduction of the CTVPTV margins compared with those applied when positioning the treatment beams based on skin marks or on bony structures [11]. In addition, inter-fraction and intra-fraction prostate motion have been studied extensively during recent years [12-14]. However, the optimal CTV-PTV margin in a specific setting is still debated [15]. When the margin is reduced to as small as $3 \mathrm{~mm}$, adequate coverage of at least larger prostates seems to be jeopardized $[16,17]$.

The CTV-PTV margin should not only take setup variations and tumour motion into account but also include any changes in the shape and size of the CTV [18]. Changes in prostate morphology during radiotherapy are not well studied. There is some evidence that prostate size increases slightly during the first week(s) after start

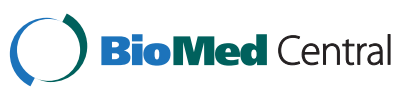


of conventionally fractionated RT and then decreases substantially during treatment and shrinks to below baseline by the end of treatment $[19,20]$.

Hypo-fractionated RT of prostate cancer has earned increased attention due to a proposed low $\alpha / \beta$ value, close to $1.5 \mathrm{~Gy}[21,22]$. The application of higher fraction doses might result in a larger change in prostate shape and size as compared with conventional fractionation, since prostate swelling is known to occur during brachytherapy [23,24].

The aim of the present study was to measure any changes in prostate size during a course of extreme hypo- fractionation delivered with external beam technique by using sequential MRI scanning before, during and at the end of the RT course. A cohort of patients from a Swedish multicentre trial (HYPO-RT-PC), studying extreme hypo-fractionation, was used for the study.

\section{Methods}

\section{Patients}

Twenty patients treated with extreme hypo-fractionation were included in the present study. All patients were recruited from an on-going Scandinavian prospective randomized phase III trial (HYPO-RT-PC), which compares extreme hypo-fractionation with conventional fractionation in intermediate risk prostate cancer patients [25]. This study was approved by the local ethics committee (Division of Oncology, Department of Clinical Sciences, Lund University) and is performed according to the Helsinki Declaration of 1975, (revised in 2000). Inclusion criteria are: age $<75$ years, WHO performance status $0-2$, intermediate risk prostate cancer with clinical category T1c-T3a with one of the following risk factors: 1) T3a, 2) Gleason $\geq$ 7 or 3) PSA $>10 \mu \mathrm{g} / \mathrm{L}$. PSA shall be $<20 \mu \mathrm{g} / \mathrm{L}$ and a biopsy-proven adenocarcinoma without any signs of spread distally or to lymph nodes are also required. Any earlier treatment for prostate cancer, previous hormonal therapy, other serious diseases (including prior malignant disease), conditions that could prevent implantation of markers into the prostate or signs of metastatic disease are exclusion criteria. Patient characteristics for the cohort in the present study are given in Table 1.

\section{Treatment}

In the HYPO-RT-PC study, patients are randomized between either conventional fractionation $(39 \times 2.0 \mathrm{~Gy}=$ 78.0 Gy given once a day, five days per week) or to an experimental arm with an extreme hypo-fractionated regimen $(7 \times 6.1 \mathrm{~Gy}=42.7$ Gy given every other weekday, and always including two weekends without RT). The trial arms are equieffective assuming $\alpha / \beta=3 \mathrm{~Gy}$, neglecting any influence of the difference in total treatment time. Both 3D-conform radiotherapy (3D-CRT) and IMRT/ VMAT techniques are allowed. Hormonal treatment is not permitted.
Table 1 Patient baseline characteristics $(n=20)$

\begin{tabular}{ll}
\hline Age & $68(59-73)$ \\
\hline Median (range) & 17 \\
\hline T1C & 3 \\
\hline T2 & \\
\hline Gleason score & 3 \\
\hline 6 & 14 \\
\hline 8 & 3 \\
\hline iPSA (ng/mL) & $10.2(4.5)$ \\
\hline Mean (SD) & $73(30)$ \\
\hline Prostate volume $\left(\mathbf{c m}^{\mathbf{3}}\right)^{*}$ & \\
\hline Mean (SD) &
\end{tabular}

\section{Radiotherapy procedure according to the HYPO-RT-PC} study protocol

Three gold markers were implanted into the prostate for daily image guidance at least three weeks before the treatment planning CT to avoid post-implant oedema of the gland. Target and OAR definitions were according to ICRU $[18,26,27]$. The CTV, i.e. prostate (no seminal vesicles), was segmented as visualised on the treatmentplanning CT (slice thickness $\leq 3 \mathrm{~mm}$ ). CT defined prostate segmentation is mandatory according to the study protocol but MRI is recommended as an aid for target delineation. The PTV includes CTV with a $7 \mathrm{~mm}$ isotropic 3D-margin. The CT-based CTV volume for the patients included in the present study was already defined within the clinical trial by three different senior radiation oncologists.

\section{Sequential MRI scanning for CTV delineation}

The patients were imaged with a Siemens Espree $1.5 \mathrm{~T}$ MR scanner (Siemens Medical, Erlangen, Germany) using a body coil and a T2 weighted high-resolution 3D sequence with axial slices (slice thickness 1.7-3.3 mm). This MRI sequence is used in clinical routine as aid for the CT-based target definition. The patients were placed in supine position with a leg fixation device on a flat tabletop insert during the MR imaging, i.e. in the same position as for RT.

MRI scans were performed at baseline (MRI baseline$_{\text {e }}$ when the patient came for treatment-planning $\mathrm{CT}$, in the middle $\left(\mathrm{MRI}_{\text {mid }}, \mathrm{EQD} 2_{3}=33 \mathrm{~Gy}\right)$ and at the end of treatment $\left(\mathrm{MRI}_{\text {end, }}, \mathrm{EQD} 2_{3}=67 \mathrm{~Gy}\right)$. The MRI studies were transferred to the treatment planning system (Nucletron Oncentra, ver 4.0) where the prostate was delineated in each MRI slice by the same radiation oncologist (AG). This delineation was done in a blinded fashion. The volume, as calculated by the treatment planning system, was registered for each $\mathrm{CTV}_{\mathrm{MRI}}$. In addition, the maximum extension of the 
delineated prostate on the MRIs was measured in the three principal directions, i.e. left-right $\left(\mathrm{x}_{\max }\right)$, anterior-posterior $\left(\mathrm{y}_{\max }\right)$ and cranial-caudal $\left(\mathrm{z}_{\max }\right)$ to estimate any changes in size in the three directions. The $\mathrm{x}_{\max }, \mathrm{y}_{\max }$ and $\mathrm{z}_{\max }$ values are hence the sides of the smallest rectangular prism which precisely contains the segmented prostate.

To test whether the average change in prostate volume at the various time points was significant, a standard two-sided t-test was used. A p-value $<0.05$ was considered significant.

\section{Results}

Segmented absolute prostate volumes together with relative prostate volume changes vs. the baseline MRI volume are given in Table 2 . The results are also presented graphically in Figure 1. The prostate volumes measured on the treatment-planning CT averaged 23\% larger than those delineated on the baseline MRI (MRI baseline$)$. The difference was statistically significant, $\mathrm{p}=0.0001$.

The median time (range) elapsed from $\mathrm{MRI}_{\text {baseline }}$ to $M R I_{\text {mid }}$ and from MRI baseline to MRI $I_{\text {end }}$ was 8 (6-9) days and 16 (15-17) days, respectively. According to the sequential MRI scanning analyses, extreme hypo-fractionation caused a $14 \%$ mean relative volume increase $(\mathrm{p}<0.0001)$ at MRI $_{\text {mid. }}$ The mean volume increase was still present at the time of the last treatment fraction $\left(9 \%\right.$ at $\mathrm{MRI}_{\text {end }}$, $\mathrm{p}=0.0002$ ). There was no significant difference in mean relative volume change between prostates above vs. below the median CTV size, neither at MRI mid $(\mathrm{p}=0.30)$ nor at $\mathrm{MRI}_{\text {end }}(\mathrm{p}=0.20)$.

The maximum prostate dimensions $\left(\mathrm{x}_{\max }, \mathrm{y}_{\max }\right.$ and $z_{\max }$ ) as defined above were unchanged in the lateral direction but increased in the anterior-posterior and cranial-caudal directions by $2-3 \mathrm{~mm}$ for $\mathrm{MRI}_{\text {mid }}$ or $\mathrm{MRI}_{\text {end }}$ as compared with baseline (see Table 3 for details). Corresponding data for "small" versus "large" prostate baseline volumes are presented in Table 4 .

\section{Discussion}

Variations in prostate size during a course of radiotherapy using conventional fractionation have been studied

Table 2 Prostate volumes in descending order as segmented on the treatment planning CT and on the MR images before radiotherapy ( $\left(\mathrm{MRI}_{\text {baseline }}\right)$, in the middle of the treatment ( $\left.M R I_{\text {mid }}\right)$ and at the end of treatment (MRI end)

\begin{tabular}{|c|c|c|c|c|c|c|c|}
\hline \multirow[t]{2}{*}{ Pat \# } & \multicolumn{2}{|c|}{$\mathrm{CT}$} & \multirow{2}{*}{$\frac{\text { MRI }_{\text {baseline }}}{\text { Abs. vol. }\left(\mathrm{cm}^{3}\right)}$} & \multicolumn{2}{|c|}{$\mathrm{MRI}_{\text {mid }}$} & \multicolumn{2}{|c|}{$\mathrm{MRI}_{\text {end }}$} \\
\hline & Abs. vol. $\left(\mathrm{cm}^{3}\right)$ & Rel. vol. & & Abs. vol. $\left(\mathrm{cm}^{3}\right)$ & Rel. vol. & Abs. vol. $\left(\mathrm{cm}^{3}\right)$ & Rel. vol. \\
\hline 1 & 35.3 & 1.579 & 22.4 & 26.7 & 1.191 & 27.2 & 1.217 \\
\hline 2 & 44.5 & 1.369 & 32.5 & 38.6 & 1.187 & 34.9 & 1.074 \\
\hline 3 & 33.8 & 0.999 & 33.9 & 39.0 & 1.151 & 33.1 & 0.976 \\
\hline 4 & 47.8 & 1.105 & 43.3 & 47.5 & 1.098 & 46.2 & 1.067 \\
\hline 5 & 45.8 & 1.054 & 43.4 & 48.9 & 1.126 & 48.7 & 1.122 \\
\hline 6 & 64.8 & 1.455 & 44.5 & 53.3 & 1.198 & 44.1 & 0.991 \\
\hline 7 & 71.6 & 1.597 & 44.8 & 49.8 & 1.112 & 46.6 & 1.040 \\
\hline 8 & 43.5 & 0.906 & 48.0 & 48.7 & 1.015 & 48.0 & 1.000 \\
\hline 9 & 79.4 & 1.648 & 48.2 & 55.5 & 1.152 & 54.4 & 1.129 \\
\hline 10 & 73.0 & 1.511 & 48.4 & 48.9 & 1.011 & 50.1 & 1.037 \\
\hline 11 & 59.4 & 1.102 & 53.9 & 60.8 & 1.128 & 55.2 & 1.023 \\
\hline 12 & 57.0 & 1.037 & 54.9 & 65.3 & 1.189 & 64.4 & 1.172 \\
\hline 13 & $-^{*}$ & $-^{*}$ & 57.2 & 66.6 & 1.166 & 62.2 & 1.089 \\
\hline 14 & 83.8 & 1.196 & 70.1 & 88.7 & 1.265 & 78.0 & 1.112 \\
\hline 15 & 99.0 & 1.347 & 73.5 & 80.0 & 1.088 & 74.1 & 1.008 \\
\hline 16 & 79.4 & 1.066 & 74.5 & 95.5 & 1.282 & 96.2 & 1.291 \\
\hline 17 & 96.5 & 1.145 & 84.3 & 96.8 & 1.148 & $-{ }_{-}^{\ddagger}$ & $-{ }^{\ddagger}$ \\
\hline 18 & 105.8 & 1.242 & 85.2 & 96.3 & 1.131 & 101.4 & 1.190 \\
\hline 19 & 106.2 & 1.021 & 104.0 & 116.8 & 1.123 & 115.6 & 1.112 \\
\hline 20 & 153.7 & 1.045 & 147.1 & 155.0 & 1.054 & 152.9 & 1.040 \\
\hline Mean & 72.7 & 1.233 & 60.7 & 68.9 & 1.141 & 64.9 & 1.089 \\
\hline SD & 30.4 & 0.232 & 28.7 & 31.3 & 0.070 & 31.9 & 0.084 \\
\hline p-value ${ }^{\dagger}$ & 0.0001 & 0.0004 & - & $<0.0001$ & $<0.0001$ & 0.0008 & 0.0002 \\
\hline
\end{tabular}

Relative volumes and $\mathrm{p}$-values are in relation to $M \mathrm{MI}_{\text {baseline. }}$

*Prostate was not segmented on CT as the patient had a hip prosthesis.

${ }^{\ddagger}$ Missing data, MRI not performed.

${ }^{\dagger}$ Paired t-test. 


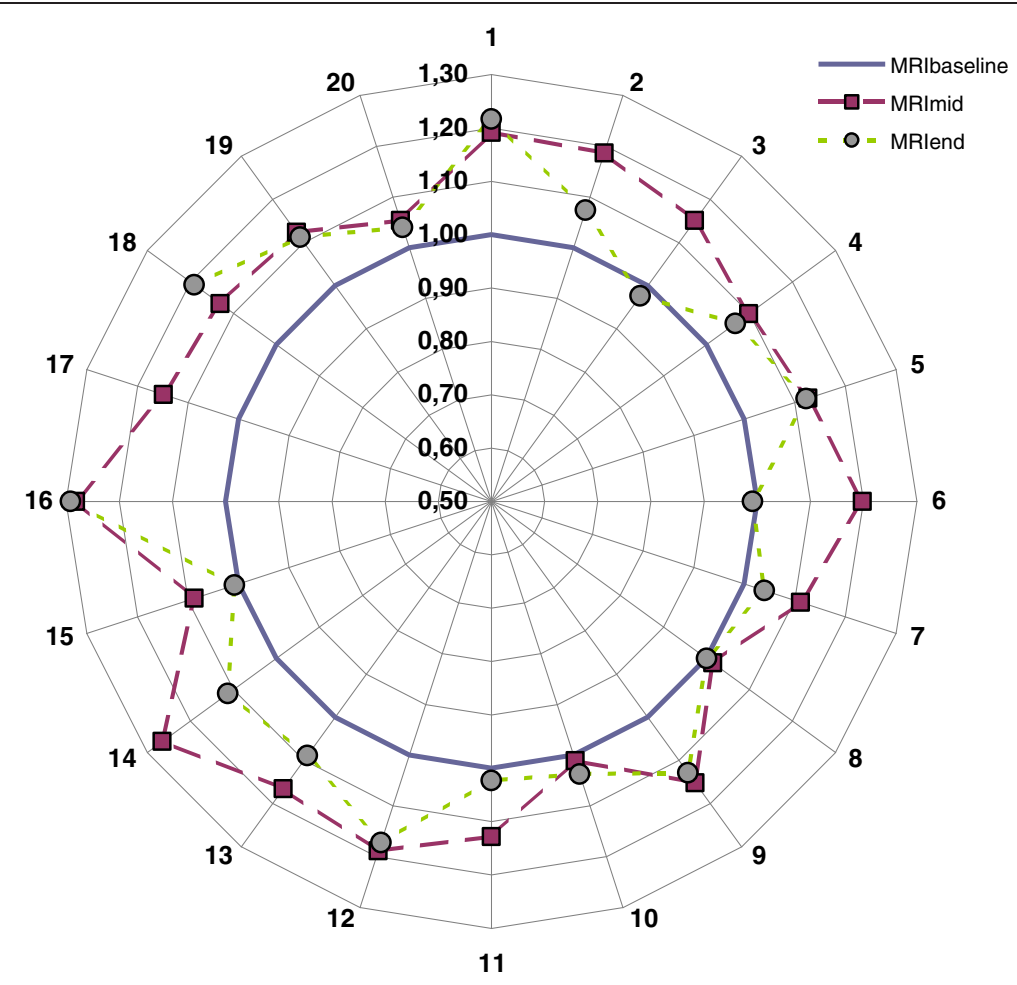

Figure 1 Relative prostate volume compared to baseline ( $\mathrm{MRI}_{\text {baseline}}$ ) at $\mathrm{MRI}_{\text {mid }}\left(\mathrm{EQD2}_{3}=33 \mathrm{~Gy}\right.$ ) (squares) and at $\mathrm{MRI} \mathrm{end}_{\mathrm{end}}$ $\left(\mathrm{EQD2}_{3}=67 \mathrm{~Gy}\right)$ (circles) for patients 1-20.

previously. Generally these studies have shown an overall prostate volume reduction at end of treatment (without any anti-hormonal treatment) as compared to baseline although with an initial volume increase $[19,20,28]$. Based on the relative position of implanted electro-magnetic transponders, King et al. showed that the prostate size increases transiently (mean 6.1\%) during the first week(s) after start of conventional RT (total dose $81 \mathrm{~Gy}, 1.8 \mathrm{~Gy} /$ fraction) and then shrinks to below baseline by the end of treatment. The decrease in mean prostate volume was $10.9 \%$ from the first to the final day of RT. Using MRI, Nichol et al. studied changes in prostate size during conventionally fractionated RT (total dose $79.8 \mathrm{~Gy}$, $1.9 \mathrm{~Gy} /$ fraction) in 25 patients. They reported a prostate volume decrease by $0.5 \% /$ fraction. Based on CT scanning at start and at the last week of RT (total dose $76 \mathrm{~Gy}$, $2.0 \mathrm{~Gy} /$ fraction), Sanguineti et al. reported a mean decrease in prostate volume of $7 \%$ in 14 patients without any antihormonal treatment.
To our knowledge there are no earlier studies on how extreme hypo-fractionation affects the prostate volume during radiotherapy. The extreme hypo-fractionation regimen used in our study lead to a significant increase in prostate volume after three treatment fractions $\left(\mathrm{EQD} 2_{3}=\right.$ 33 Gy). This increase was still apparent at the end of treatment after six fractions (EQD2 $2_{3}=67$ Gy). Our observations indicate that the enlargement of the CTV is both larger than that known for conventional therapy and stays enlarged during the whole treatment course. This could be an important factor to take into account when choosing margin size.

When using daily imaging for set up correction, a minimum margin size between $1.5-3 \mathrm{~mm}$ to compensate for intra-fraction motion of the prostate has been proposed as adequate $[15,16]$. Our results indicate that a margin extension of similar magnitude (covering the $95 \%$ CIs in Table 3) could be needed to take prostate swelling into account during extreme hypo-fractionation. The analysis of prostate

Table 3 Average change in maximum prostate extension in lateral $\left(\Delta \mathbf{x}_{\max }\right)$, anterior-posterior $\left(\Delta \mathbf{y}_{\max }\right)$ and $c r a n i a l-c a u d a l$ $\left(\Delta \mathrm{z}_{\text {max }}\right.$ ) direction (mean values and $95 \% \mathrm{Cl}$ )

\begin{tabular}{|c|c|c|c|c|c|c|}
\hline & $\Delta \mathrm{x}_{\max }(\mathrm{mm})$ & $P$ & $\Delta y_{\max }(\mathrm{mm})$ & $p$ & $\Delta \mathrm{z}_{\max }(\mathrm{mm})$ & $p$ \\
\hline$M R_{\text {mid }}-M R_{\text {baseline }}$ & $0.2(-1.1-1.5)$ & 0.72 & $3.3(1.8-4.8)$ & 0.0002 & $2.5(1.0-3.9)$ & 0.0019 \\
\hline$M R_{\text {end }}-M R_{\text {baseline }}$ & $0.3(-0.9-1.4)$ & 0.60 & $2.0(0.5-3.4)$ & 0.010 & $2.0(0.8-3.1)$ & 0.0029 \\
\hline$M R_{\text {end }}-M R_{\text {mid }}$ & $0.1(-0.8-0.9)$ & 0.89 & $-1.4(-2.7--0.1)$ & 0.036 & $-0.6(-1.7-0.6)$ & 0.32 \\
\hline
\end{tabular}


Table 4 Average change in maximum prostate extension in lateral $\left(\Delta \mathbf{x}_{\max }\right)$, anterior-posterior $\left(\Delta \mathbf{y}_{\max }\right)$ and cranial-caudal $\left(\Delta z_{\text {max }}\right)$ direction for "small"/"large" prostate volumes, i.e. below/above median MRI baseline volume $\left(=50 \mathrm{~cm}^{3}\right)$

\begin{tabular}{|c|c|c|c|c|c|c|}
\hline & $\Delta \mathrm{x}_{\max }(\mathrm{mm})$ & $p$ & $\Delta y_{\max }(\mathrm{mm})$ & $p$ & $\Delta \mathrm{z}_{\max }(\mathrm{mm})$ & $p$ \\
\hline$M R_{\text {mid }}-M R_{\text {baseline }}$ & $-0.5 / 1.0$ & 0.24 & $3.3 / 3.3$ & 0.98 & $1.9 / 3.0$ & 0.44 \\
\hline$M R_{\text {end }}-M R_{\text {baseline }}$ & $-0.1 / 0.7$ & 0.44 & $1.3 / 2.8$ & 0.29 & $1.9 / 2.0$ & 0.88 \\
\hline$M R_{\text {end }}-M R_{\text {mid }}$ & $0.0 / 0.0$ & 0.41 & $-0.2 /-0.1$ & 0.24 & $0.0 /-0.1$ & 0.34 \\
\hline
\end{tabular}

distension showed that the prostate seemed to swell most profoundly in the anterior-posterior and cranial-caudal directions. This might indicate that a margin reduction towards the rectum should be applied with caution, especially during extreme hypo-fractionation. The difference in prostate expansion in cranial-caudal and anterior-posterior directions on one hand and lateral direction on the other hand could be due to the pelvic side wall acting as an anatomic barrier [19].

Prostate swelling during brachytherapy is well known $[23,24]$, and thus one could expect larger swelling when using hypo-fractionation than during conventional radiotherapy treatment. Our study supports this and sparks concerns that larger treatment margins are indicated with this kind of regimen as compared with conventional treatment, especially if prostate segmentation is based on MRI only. MRI-based contouring at baseline resulted in a CTV volume that was about $20 \%$ smaller than the volume generated in the original treatment-planning CT which is in concordance with an earlier study by Smith et al. [29] who found an average difference of $16 \%$. Inferior soft tissue contrast on CT as compared to MRI increases inter-observer variability in CT-based target definition which can partly explain this difference in volume between CT and MRI. The fact that current clinical evidence in prostate cancer radiotherapy is generated from CT-based target definition, implies that great care has to be taken to compensate for prostate swelling if the segmentation and treatment planning process is performed with MR-only [30]. We also looked at whether patients with larger prostate glands experienced more swelling than patients with smaller glands. No such difference in relative prostate volume change was observed.

To minimize multi-observer variation in prostate segmentation as well as MRI-sequence based errors [31], the same radiation oncologist did the delineation in a blinded fashion on the same MRI-sequence at each time-point. The fact that the prostate increased in volume at midtreatment as compared to baseline for all patients supports that this is due to a true treatment induced swelling and not a methodological error. One could also argue that image guided set-up correction would cope with this change in prostate shape during the course of treatment. However, this correction usually involves three markers implanted centrally in the prostate gland, and thus it is probably adequate for prostate motion but less adequate for taking changes in the outer boundaries of the gland into consideration. Re-contouring of the prostate volume followed by re-planning before each fraction could be needed when using narrow margins $(\leq 3 \mathrm{~mm})$.

\section{Conclusions}

Our study indicates that the prostate swells significantly during external radiotherapy when using extreme hypofractionation. This seems to be an important factor when defining margin size for extreme hypo-fractionation schedules for prostate cancer to minimize the risk of treatment failure when using narrow margins. In order to take prostate swelling into account when using extreme hypofractionation, we conclude that up to $2 \mathrm{~mm}$ extra margin could be needed if prostate segmentation is based only on MRI. Adaptive radiotherapy with re-planning before each fraction, which would also take changes in prostate shape into consideration, would be optimal.

We are planning a larger study on prostate volume change within the frame of the HYPO-RT-PC trial also including conventional fractionation for comparison.

\section{Consent}

Written informed consent was obtained from all patients included in this study.

\section{Competing interests}

All authors declare that they have no competing interests.

\section{Authors' contributions}

$A G$, EK and PN designed the study, retrieved and analysed the data and drafted the manuscript. $\mathrm{OH}$ gave statistical advice and revised the manuscript. CTK and AW were involved in the study design and revised the manuscript. All authors read and approved the final manuscript.

\section{Acknowledgements}

We would like to thank Birgitta Bern and Nils-Olof Karlsson at the Department of Radiotherapy in Umeå for all help with MRI scanning.

\section{Author details}

'Department of Oncology, Skåne University Hospital, Lund University, 22185 Lund, Sweden. 'Department of Epidemiology, Skåne University Hospital, Lund University, 22185 Lund, Sweden. ${ }^{3}$ Department of Oncology and Department of Radiation Sciences, Umeå University Hospital, SE-901 85 Umeå, Sweden. ${ }^{4}$ Department of Oncology and Radiation Physics, Skåne University Hospital, Lund University, 22185 Lund, Sweden.

Received: 11 August 2013 Accepted: 3 January 2014

Published: 13 January 2014 


\section{References}

1. Balter JM, Lam KL, Sandler HM, Littles JF, Bree RL, Ten Haken RK: Automated localization of the prostate at the time of treatment using implanted radiopaque markers: technical feasibility. Int J Radiat Oncol Biol Phys 1995, 33:1281-1286

2. Balter JM, Chen GTY, Pelizzari CA, Krishnasamy S, Rubin S, Vijayakumar S: Online repositioning during treatment of the prostate: a study of potential limits and gains. Int J Radiat Oncol Biol Phys 1993, 27:137-143.

3. Ploeger LS, Frenay M, Betgen A, de Bois JA, Gilhuijs KG, van Herk M: Application of video imaging for improvement of patient set-up. Radiother Oncol 2003, 68:277-284.

4. Nyholm T, Nyberg M, Karlsson MG, Karlsson M: Systematisation of spatial uncertainties for comparison between a MR and a CT-based radiotherapy workflow for prostate treatments. Radiat Oncol 2009, 17(4):54.

5. Kuban DA, Tucker SL, Dong L, Starkschall G, Huang EH, Cheung MR, Lee AK, Pollack A: Long-term results of the M. D. Anderson randomized dose-escalation trial for prostate cancer. Int J Radiat Oncol Biol Phys 2008, 70:67-74.

6. Zelefsky MJ, Yamada Y, Fuks Z, Zhang Z, Hunt M, Cahlon O, Park J, Shippy A: Long-term results of conformal radiotherapy for prostate cancer: impact of dose escalation on biochemical tumor control and distant metastases-free survival outcomes. Int J Radiat Oncol Biol Phys 2008, 71:1028-1033

7. Zelefsky MJ, Chou JF, Pei X, Yamada Y, Kollmeier M, Cox B, Zhang Z, Schechter M, Cohen GN, Zaider M: Predicting biochemical tumor control after brachytherapy for clinically localized prostate cancer: the memorial Sloan-Kettering cancer center experience. Brachytherapy 2012, 11:245-249.

8. Michalski J, Winter K, Roach M, Markoe A, Sandler HM, Ryu J, Parliament M, Purdy JA, Valicenti RK, Cox JD: Clinical outcome of patients treated with 3D conformal radiation therapy (3D-CRT) for prostate cancer on RTOG 9406. Int J Radiat Oncol Biol Phys 2012, 83:363-370.

9. Schulz RJ, Kagan AR: Dose escalation in the radiation therapy of prostate cancer. Int J Radiat Oncol Biol Phys 2011, 80:1289-1291.

10. Fransson P, Bergstrom P, Lofroth P-O, Widmark A: Five-year prospective patient evaluation of bladder and bowel symptoms after dose-escalated radiotherapy for prostate cancer with the BeamCath technique. Int J Radiat Oncol Biol Phys 2006, 66:430-438.

11. van Herk M: Errors and margins in radiotherapy. Semin Radiat Oncol 2004, 14:52-64.

12. Ghilezan MJ, Jaffray DA, Siewerdsen JH, Van Herk M, Shetty A, Sharpe MB, Zafar Jafri S, Vicini FA, Matter RC, Brabbins DS, Martinez AA: Prostate gland motion assessed with cine-magnetic resonance imaging (cine-MRI). Int $J$ Radiat Oncol Biol Phys 2005, 62:406-417.

13. Malone S, Crook JM, Kendal WS, Zanto JS: Respiratory-induced prostate motion: quantification and characterization. Int J Radiat Oncol Biol Phys 2000, 48:105-109.

14. Budiharto $T$, Slagmolen $P$, Haustermans $K$, Maes F, Junius $S$, Verstraete J, Oyen R, Hermans J, Van den Heuvel F: Intrafractional prostate motion during online image guided intensity-modulated radiotherapy for prostate cancer. Radiother Oncol 2011, 98:181-186.

15. Enmark M, Korreman S, Nystrom H: IGRT of prostate cancer; is the margin reduction gained from daily IG time-dependent? Acta Oncol 2006, 45:907-914.

16. Melancon AD, Daniel JC O, Zhang L, Kudchadker RJ, Kuban DA, Lee AK, Cheung RM, de Crevoisier R, Tucker SL, Newhauser WD, Mohan R, Dong L: Is a 3-mm intrafractional margin sufficient for daily image-guided intensity-modulated radiation therapy of prostate cancer? Radiother Oncol 2007, 85:251-259.

17. Engels B, Soete G, Verellen D, Storme G: Conformal arc radiotherapy for prostate cancer: Increased biochemical failure in patients with distended rectum on the planning computed tomogram despite image guidance by implanted markers. Int J Radiat Oncol Biol Phys 2009, 74:388-391.

18. International Commission of Radiation Units and Measurements: ICRU report 83: Prescribing, Recording, and Reporting Photon-Beam Intensity-Modulated Radiation Therapy (IMRT). Journal of the ICRU 2010, 10:1.

19. King BL, Butler WM, Merrick GS, Kurko BS, Reed JL, Murray BC, Wallner KE: Electromagnetic transponders indicate prostate size increase followed by decrease during the course of external beam radiation therapy. Int $J$ Radiat Oncol Biol Phys 2010, 79:1350-1357.

20. Nichol AM, Brock KK, Lockwood GA, Moseley DJ, Rosewall T, Warde PR, Catton CN, Jaffray DA: A magnetic resonance imaging study of prostate deformation relative to implanted gold fiducial markers. Int I Radiat Oncol Biol Phys. 2007, 67:48-56.
21. Miralbell R, Roberts SA, Zubizarreta E, Hendry JH: Dose-fractionation sensitivity of prostate cancer deduced from radiotherapy outcomes of 5,969 patients in seven international institutional datasets: $\alpha / \beta=1.4$ (0.9-2.2) Gy. Int J Radiat Oncol Biol Phys 2012, 82:17-24.

22. Fowler J, Chappell R, Ritter M: Is alpha/beta for prostate tumours really low? Int J Radiat Oncol Biol Phys 2001, 50:1021-1031.

23. Kono Y, Kubota K, Aruga T, Ishibashi A, Morooka M, Ito K, Itami J, Kanemura M, Minowada S, Tanaka T: Swelling of the prostate gland by permanent brachytherapy may affect seed migration. Jpn J Clin Oncol 2010, 40:1159-1165.

24. Chung E, Stenmark MH, Evans C, Narayana V, McLaughlin PW: Greater postimplant swelling in small-volume prostate glands: Implications for dosimetry, treatment planning, and operating room technique. Int J Radiat Oncol Biol Phys 2012, 82:1944-1948.

25. ISRCTN: Phase III study of HYPO-fractionated radiotherapy of intermediate risk localised prostate cancer. http://www.controlled-trials.com/ ISRCTN45905321.

26. International Commission of Radiation Units and Measurements, ICRU report 50: Prescribing, Recording, and Reporting Photon-Beam Therapy. Bethesda; 1993. ICRU; 1993 (ISBN 0-913394-48-3).

27. International Commission on Radiation Units and Measurements, ICRU report 62: Prescribing, recording, and reporting photon beam therapy (supplement to ICRU report 50). Bethesda; 1999. ICRU; 1999 (ISBN 0-913394-61-0).

28. Sanguineti G, Marcenaro M, Franzone P, Foppiano F, Vitale V: Neoadjuvant androgen deprivation and prostate gland shrinkage during conformal radiotherapy. Radiother Oncol 2003, 66:151-157.

29. Smith W, Lewis C, Bauman G, Rodrigues G, D'Souza D, Ash R, Ho D, Venkatesan $V$, Downey D, Fenster A: Prostate volume contouring: a 3D analysis of segmentation using 3DTRUS, CT, and MR. Int I Radiat Oncol Biol Phys 2007, 67:1238-1247.

30. Jonsson JH, Karlsson MG, Karlsson M, Nyholm T: Treatment planning using MRI data: an analysis of the dose calculation accuracy for different treatment regions. Radiat Oncol 2010, 30:62.

31. Nyholm T, Jonsson J, Söderström K, Bergström P, Carlberg A, Frykholm G, Behrens CF, Geertsen PF, Trepiakas R, Hanvey S, Sadozye A, Ansari J, McCallum H, Frew J, McMenemin R, Zackrisson B: Radiat Oncol 2013, 24:126. Epub ahead of print.

doi:10.1186/1748-717X-9-22

Cite this article as: Gunnlaugsson et al:: Change in prostate volume during extreme hypo-fractionation analysed with MRI. Radiation Oncology 2014 9:22.

\section{Submit your next manuscript to BioMed Central and take full advantage of:}

- Convenient online submission

- Thorough peer review

- No space constraints or color figure charges

- Immediate publication on acceptance

- Inclusion in PubMed, CAS, Scopus and Google Scholar

- Research which is freely available for redistribution 